\title{
Potencial presencia del castor norteamericano en el Parque Nacional Cabo de Hornos
}

\author{
Potential presence of the North American beaver \\ in Cape Horn National Park
}

Alejandro Huertas Herrera ${ }^{1}$, Mónica Toro Manríquez ${ }^{1}$, René Muñoz ${ }^{2}$, Christopher B. Anderson ${ }^{1,3}$, Guillermo Martínez Pastur ${ }^{1}$

Comprender la distribución del castor norteamericano (Castor canadensis Kuhl, 1820), cuya expansión en la Patagonia austral data desde el año 1946 con su introducción desde Canadá a la isla Grande de Tierra del Fuego (Pietrek \& Fasola, 2014), es relevante para la investigación ecológica básica y crítica para tomar decisiones de gestión en el sur de Chile y Argentina. Debido a sus extensos impactos en el sur de la Patagonia, la invasión del castor se considera una prioridad científica y para la conservación de los ambientes (Anderson et al. 2011).

Los castores han invadido gran parte del archipiélago de Tierra del Fuego argentinochileno y se estiman que en sólo el lado argentino han afectado más de 30.000 ha en la isla Grande, ocupando todos los ambientes abiertos (e.g. estepa, turberas), y forestales (bosques de Nothofagus spp. como ñirre, lenga y coigüe de Magallanes), con elevaciones que varían desde el nivel del mar y hasta el límite arbóreo (promedio $1.400 \mathrm{msnm}$ ) (Henn et al. 2016). Esta especie se ha establecido en diversos ecosistemas, afectando hábitats terrestres y acuáticos, no solo a nivel de comunidades bióticas, sino que también la función ecosistémica a nivel de paisaje (Anderson et al. 2014), dañando gravemente a los bosques ribereños (Baldini et al. 2008; Henn et al. 2016). Se ha demostrado (e.g. Martínez Pastur et al. 2006) que el daño del castor en el bosque ribereño puede durar mucho tiempo $y$ transformarlos a un estado estable de pastizal y/o praderas húmedas (beaver meadow en inglés), y alterando las comunidades de herbáceas mono y dicotiledóneas luego de 20 años de impacto (Wallem et al. 2010). Algo similar ocurre con el establecimiento de la regeneración del bosque de Nothofagus (Toro Manríquez, 2014; Henn et al. 2014).

La invasión del castor se ha documentado principalmente en el Archipiélago Fueguino, pero a partir de los años 90 también existen registros confirmados en la zona continental, incluyendo la Laguna Parrillar (al sur de la ciudad de Punta Arenas, Provincia de Magallanes, Chile) y más recientemente en las cercanías de la ciudad de Puerto Natales (Provincia de Última Esperanza, Chile) (Sanguinetti et al. 2014). Hasta la fecha, no se han confirmado registros en algunos lugares remotos del archipiélago, como la Isla de los Estados (Argentina) y el Archipiélago Wollaston que constituye el Parque Nacional Cabo de Hornos (Anderson et al. 2006; Valenzuela et al. 2014),

1 Centro Austral de Investigaciones Científicas, Consejo Nacional de Investigaciones Científicas y Técnicas, Houssay 200, Ushuaia,

Tierra del Fuego (9410), Argentina.

$\varangle$ ahuertasherrera@cadic-conicet.gob.ar; monicatm@cadic-conicet.gob.ar; canderson@untdf.edu.ar; cadicforestal@gmail.com

2 Departamento de Ciencias Agropecuarias y Acuícolas. Universidad de Magallanes, Chile. rene.munoz@umag.cl

3 Instituto de Ciencias Polares, Ambiente y Recursos Naturales, Universidad Nacional de Tierra del Fuego, Onas 440, Ushuaia, Tierra del Fuego (9410), Argentina 


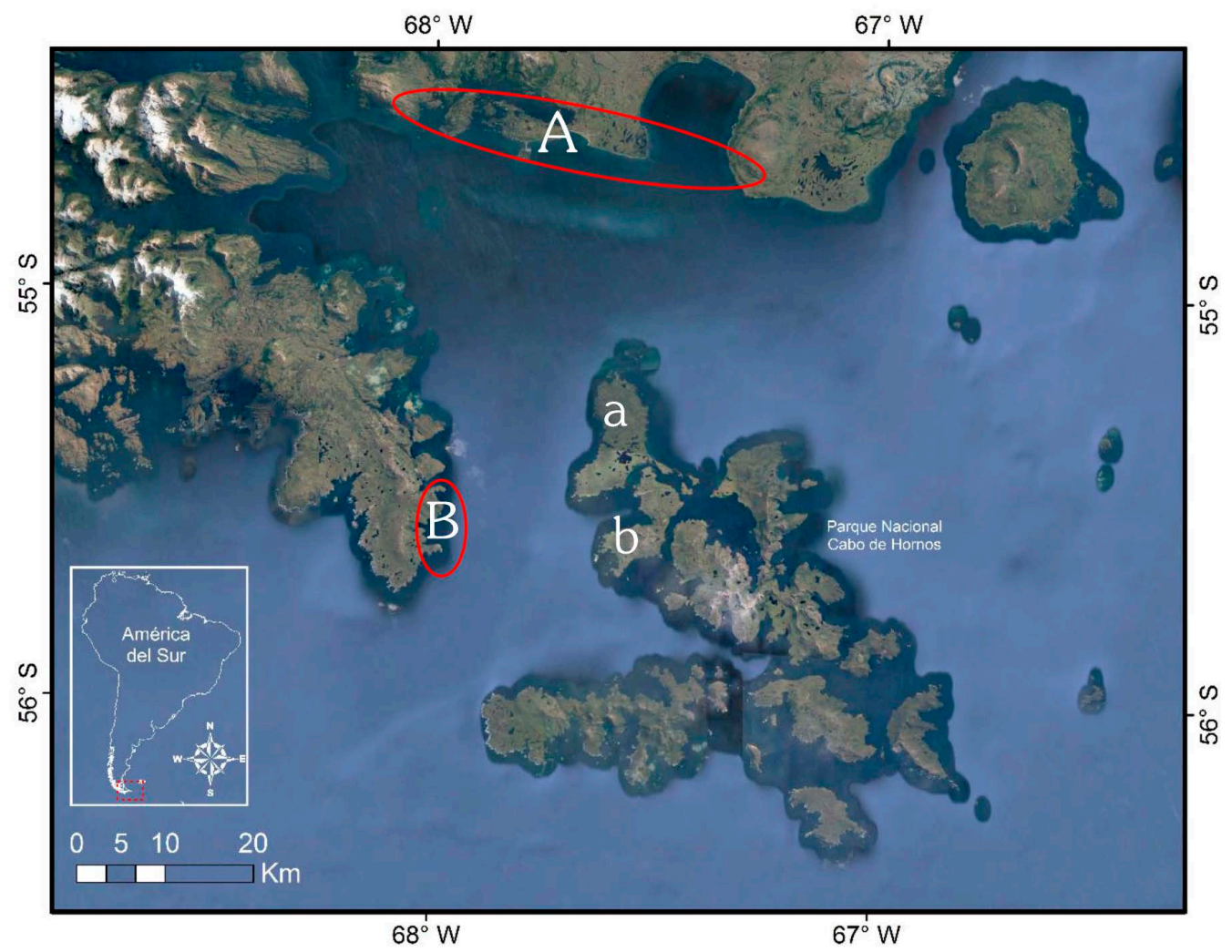

Fig. 1. Posible procedencia del castor hacia las islas del Cabo de Hornos. En letra mayúscula: A. sur de Isla Navarino; B. sureste de la Comuna de Cabo de Hornos. En letra minúscula: a. Isla Grevy; b. Isla Bayly. Imágen de Google Earth®.

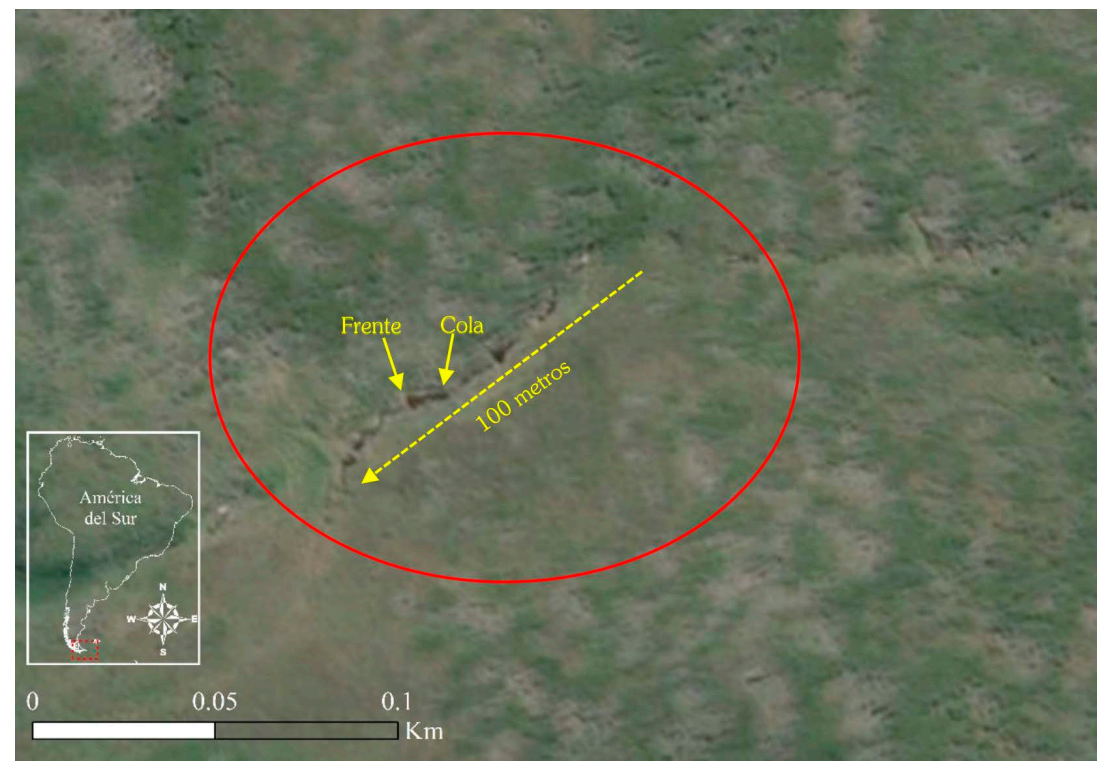

Fig. 2. Forma y patrón de castoreras en el noreste de Isla Grevy. Imágen de Google Earth®. 
pero Anderson et al. (2009) habían advertido sobre la amenaza latente de la invasión de castor en Cabo de Hornos. Por lo tanto, el objetivo de esta nota fue realizar un reconocimiento espacial de la potencial invasión del castor en la Reserva de Biosfera Cabo de Hornos (RBCH), con énfasis en las islas que corresponden al Parque Nacional Cabo de Hornos.

En este contexto, las imágenes satelitales resultan útiles para el estudio de distribución del castor en lugares remotos o difícil acceso. A partir de un reconocimiento visual de castoreras en imágenes de alta resolución espacial disponibles en Google Earth® (http://earth.google.com), se realizaron recorridos (transectas) en sentido Este-Oeste en toda la Reserva de Biosfera Cabo de Hornos (RBCH), a $1 \mathrm{~km}$ de "altura visual o de Ojo". En lugares de conocida ocupación de castores, se identificaron las castoreras a partir del reconocimiento del área de inundación (frente y cola) y patrón de ordenamiento espacial (una imagen seguida de la otra). Asimismo, se distinguieron como castoreras activas a la fecha de la imagen (mantienen lámina de agua) e inactivas (no mantienen lámina de agua). Se analizó el cambio multitemporal (e.g. castorera abandonada) con el historial de imágenes que provee Google Earth ${ }^{\circledR}$ (fecha de imágenes disponibles: marzo 2003, diciembre 2009, enero 2011, diciembre 2014). Luego
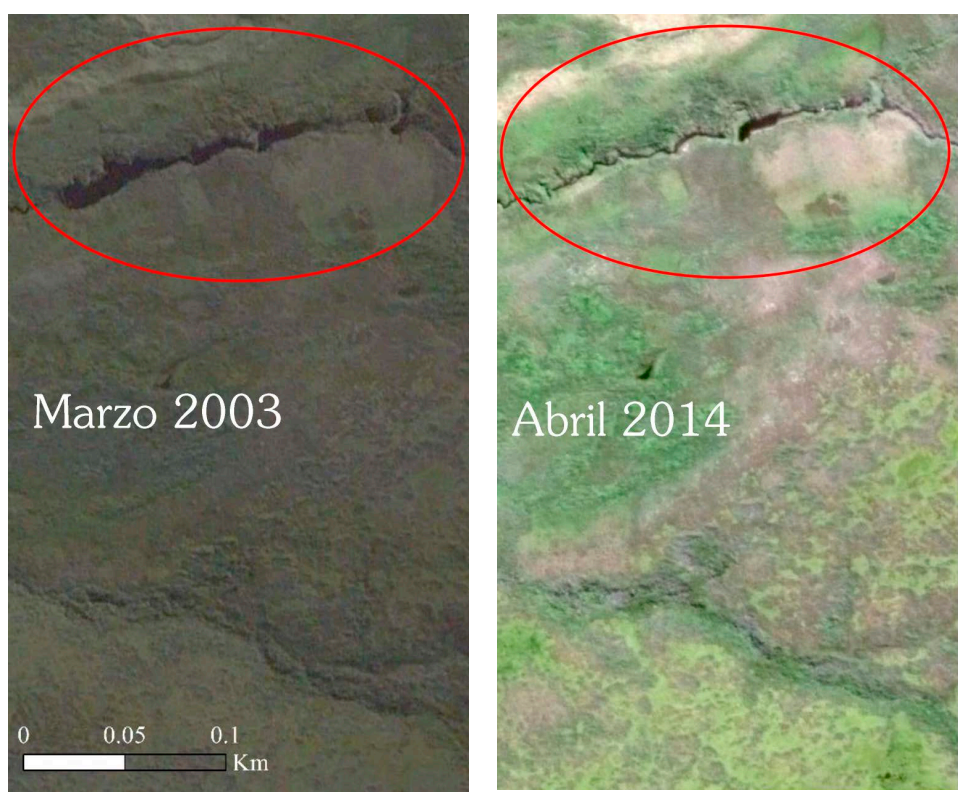

de esta experiencia se expandió la búsqueda a las áreas de la $\mathrm{RBCH}$ que actualmente no cuentan con registros de castores. La fecha del reconocimiento de castoreras en el historial de imágenes fue en noviembre de 2017.

Se detectaron dos sitios con indicios de presencia de castor (Figs. 1 a y b): (i) noreste

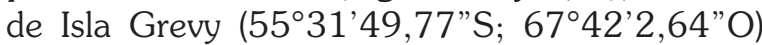

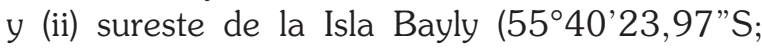
6740'19,89"O). En Isla Grevy cuatro castoreras, de un área promedio de 0,1 ha, estarían activas al año 2011. La distancia desde el punto más cercano con presencia de castores es de $24 \mathrm{~km}$, en el sureste de la Comuna de Cabo de Hornos (55³9'19,09"S; 68²'6,61"O), y de 28 km desde el sur de Isla Navarino (55¹6'27,07"S; 67²9'25,17"O). Además, una castorera activa de 0,4 ha en el sureste $\left(55^{\circ} 35^{\prime} 27,45^{\prime \prime} \mathrm{S}\right.$; $67^{\circ} 42^{\prime} 29,07^{\prime \prime O}$ ). En Isla Bayly, cuatro castoreras con un área promedio de 0,3 ha, de las cuales 5 estarían abandonadas y una activa al año 2014. La distancia desde el punto más cercano con presencia de castores en el continente es de $22 \mathrm{~km}$, en el sureste de la Comuna de Cabo de Hornos (55³9'19,09"S; 68²'6,61”O). De haber llegado el castor desde estos puntos, la Isla de los Estados, que está a $32 \mathrm{~km}$ al punto más cercano con presencia de castor, en península Mitre (ubicado el sur-este de la Isla Grande Tierra del Fuego) podría eventualmente ser invadida.

Dado la calidad de las imágenes y la forma de las coberturas, existe evidencia sólida que indica la presencia del castor en las Islas Grevy y Bayly, en el Parque Nacional Cabo de Hornos, pues las formas y patrón de ordenamiento espacial de las castoreras fueron similares a las que se han visualizado $y$ subsecuentemente verificado en la Isla Grande de Tierra del Fuego (Henn et al. 2016) y otras partes de la misma $\mathrm{RBCH}$. Presentamos esta información para ayudar con la orientación de los esfuerzos de control

Fig. 3. Posibles castoreras abandonadas en Isla Bayly. Imágenes del año 2003 y 2014 de Google Earth ${ }^{\circledR}$. 
y erradicación que se planifican actualmente en el contexto de un acuerdo binacional entre Argentina y Chile. Además, este hallazgo podría respaldar aseveraciones previas de que esta invasión biológica es la alteración más grande a los bosques más australes del mundo en la actualidad (Anderson et al. 2009; Henn et al. 2016), y podría servir como base para ayudar con la orientación del control de los castores o los esfuerzos de erradicación en Argentina y Chile.

\section{AGRADECIMIENTOS}

Queremos agradecer al Grupo de Observación de la Patagonia Austral (GOPA). Al honorable cónsul de Chile en Ushuaia, Sr. Luciano Parodi. Al Laboratorio de Recursos Agroforestales (CADIC-CONICET).

\section{LITERATURA CITADA}

Anderson, C. B., Rozzi, R., Torres-Mura, J. C., Mcgehee, S. M., Sherriffs, M. F., Schü،ttler, E., \& Rosemond, A. D. (2006). Exotic vertebrate fauna in the remote and pristine sub-Antarctic Cape Horn Archipelago region of Chile. Biodiversity and Conservation, 15, 3295-3313.

Anderson, C. B., Martínez Pastur, G., Lencinas, M. V., Wallem P. K., Moorman, M. Y., \& Rosemond, A. (2009). Do introduced North American beavers engineer differently ir southern South America? An overview with implications for restoration. Mammal Review, 39, 33-52.

Anderson, C. B., Soto, N., Cabello, J. L., Wallem, P. K., Martínez Pastur, G., Lencinas, M. V., Antúnez, D., \& Davis, E. (2011). Building alliances between research and management to better control and mitigate the impacts of an invasive ecosystem engineer: the pioneering example of the North American beaver in the Fuegian Archipelago of Chile and Argentina. En Francis, R. (Ed.), A Handbook of Global Freshwater Invasive Species (pp. 347-359). Earthscan Publishing, London,

Anderson, C. B., Lencinas, M. V., Valenzuela, A. E. J, Simononok, M. P., Wallem, P. K., \&
Martinez Pastur, G. (2014). Ecosystem engineering by an invasive species, the beaver, increases landscape-level ecosystem function but does not affect biodiversity in Tierra del Fuego's freshwater systems. Diversity and Distributions, 20, 214-222.

Baldini, A., Oltremari, J., \& Ramírez, M. (2008). Impacto del castor (Castor canadensis, Rodentia) en bosques de lenga (Nothofagus pumilio) de Tierra del Fuego, Chile. Bosque, 29, 162-169.

Henn, J. J., Anderson, C. B., Kreps, G., Lencinas, M. V., Soler Esteban, R. \& Martinez Pastur G. (2014). Determining abiotic and biotic drivers that limit active riparian forest restoration in abandoned beaver meadows in Tierra del Fuego. Ecological Restoration, 32, 369-378.

Henn, J. J., Anderson, C. B., \& Martínez Pastur, G. (2016). Landscape-level impact and habitat factors associated with invasive beaver distribution in Tierra del Fuego. Biological Invasions, 18, 1679-1688.

Martínez-Pastur, G., Lencinas, M. V., Escobar, J., Quiroga, P., Malmierca, L. Y., \& Lizarralde M. (2006). Understorey succession in Nothofagus forests in Tierra del Fuego (Argentina) affected by Castor canadensis. Journal of Applied Vegetation Science, 9, 143-154.

Pietrek, A. G., \& Fasola, L. (2014). Origin and history of the beaver introduction in South America. Mastozoología Neotropical, 21, 355-359.

Sanguinetti, J., Buria, L., Malmierca, L., Valenzuela A. E. J, Nuñez, C., Pastore, H., Chauchard, L.,... \& Chehébar, C. (2014). Manejo de especies exóticas invasoras en Patagonia, Argentina: Priorización, logros y desafíos de integración entre ciencia y gestión identificados desde la Administración de Parques Nacionales. Ecología Austral, 24, 183-192.

Toro-Manríquez, M. (2014). Regeneración de lenga en micrositios de sectores perturbados y no perturbados por efectos del Castor canadensis Kuhl en Tierra del Fuego. Memoria para optar al Título Profesional de Ingeniero Forestal. Facultad de Ciencias Forestales y de la Conservación de la 
Naturaleza, Universidad de Chile.

Valenzuela, A. E. J., Anderson, C. B., Fasola, L., \& Cabello, J.L. (2014). Linking invasive exotic species and their ecosystem impacts in Tierra del Fuego to test theory and determine action. Acta Oecologica, 54, 110-118.
Wallem, P. K., Anderson, C. B., Martínez Pastur, G., \& Lencinas, M. V. (2010). Community re-assembly by an exotic herbivore, Castor canadensis, in subantarctic forests, Chile and Argentina. Biological Invasions, 12, 325-335. 
